\title{
Amphetamine Withdrawal Alters Bistable States and Cellular Coupling in Rat Prefrontal Cortex and Nucleus Accumbens Neurons Recorded In Vivo
}

\author{
Shao-Pii Onn and Anthony A. Grace \\ Departments of Neuroscience and Psychiatry, University of Pittsburgh, Pittsburgh, Pennsylvania 15260
}

Repeated amphetamine administration is known to produce changes in corticoaccumbens function that persist beyond termination of drug administration. We have found previously that long-term alteration in dopamine systems leads to changes in gap junction communication, expressed as dye coupling, between striatal neurons. In this study, the cellular bases of amphetamine-induced changes were examined using in vivo intracellular recordings and dye injection in ventral prefrontalaccumbens system neurons of control and amphetaminetreated rats. Rats that had been withdrawn from repeated amphetamine displayed a significant increase in the incidence of dye coupling in the prefrontal cortex and nucleus accumbens, which persisted for up to $28 \mathrm{~d}$ after withdrawal. The increased coupling was limited to projection neurons in both prefrontal cortical and accumbens brain regions, as identified by their axonal trajectory or the absence of interneuronselective immunocytochemical markers. These changes oc- curred with no substantial loss of tyrosine hydroxylaseimmunoreactive terminals in these cortical and accumbens regions, ruling out dopamine degeneration as a precipitating factor. Previous studies showed that nitric oxide plays a role in the regulation of coupling; however, amphetamine-withdrawn rats had fewer numbers of neurons and processes that stained for nitric oxide synthase immunoreactivity. In amphetaminetreated rats, a higher proportion of cortical cells fired in bursts, and a larger proportion of accumbens and prefrontal cortical neurons exhibited bistable membrane oscillations. By increasing corticoaccumbens transmission, amphetamine withdrawal may lead to neuronal synchronization via gap junctions. Furthermore, this adaptation to amphetamine treatment persists long after the drug is withdrawn.

Key words: addiction; psychostimulant; amphetamine; prefrontal cortex; nucleus accumbens; electrophysiology; electrotonic transmission; synchronization
The prefrontal cortex (PFC) and ventral striatum receive extensive dopaminergic (DA) inputs from the ventral tegmental area (Fuxe et al., 1974; Berger, 1992; Williams and Goldman-Rakic, 1998), and these regions regulate motivation-related behaviors (Koob and Bloom, 1988; Schultz et al., 1992; Wise, 1996). Psychostimulants such as amphetamine increase extracellular DA levels in the PFC and nucleus accumbens (Kalivas and Duffy, 1990; Reid et al., 1997; Rawls and McGinty, 1998) via blockade of the uptake and enhancing nonvesicular release of amines (Ritz et al., 1987; Kuhar et al., 1991; Sulzer et al., 1995). Repeated intermittent administration of psychostimulants causes a progressive augmentation of motor responses that can be demonstrated with a psychostimulant challenge even weeks after terminating the repeated dosing paradigm. This phenomenon is called behavioral sensitization (Robinson and Becker, 1986; Kalivas and Stewart, 1991; Prasad et al., 1999). Amphetamine-induced sensitization is persistent for at least 1 year after withdrawal (Paulson et al., 1991; White and Wolf, 1991; Valadez and Schenk, 1994). The anatomical adaptations that underlie behavioral sensitization in rats may model the adaptive process that contributes to drug

Received Sept. 21, 1999; revised Dec. 23, 1999; accepted Dec. 29, 1999.

This work was supported by United States Public Health Service Grants MH 01055, MH 292670, MH57440, and MH 45156. We thank Dr. Susan Sesack for insightful discussions on quantification of anatomy. We also thank Nicole MacMurdo for providing excellent histology assistance and Brian Lowry for providing excellent computer programs for data acquisition and analysis.

Correspondence should be addressed to Dr. Shao-Pii Onn, 464 Crawford Hall, Department of Neuroscience, University of Pittsburgh, Pittsburgh, PA 15260. Email: onn@bns.pitt.edu.

Copyright (C) 2000 Society for Neuroscience $\quad 0270-6474 / 00 / 202332-14 \$ 15.00 / 0$ craving that occurs during withdrawal in humans after amphetamine binging. Human drug craving corresponds to an activation of frontal cortical regions (Grant et al., 1996; Maas et al., 1998; Childress et al., 1999), and alterations within the prefrontalaccumbens circuit are proposed to play a central role in the sensitization, cognitive dysfunction, negative affect, and drugseeking behavior associated with drug abuse (Robbins, 1991; Jentsch and Taylor, 1999).

One response that often occurs after long-term manipulations of DA transmission in the striatum is an alteration in dye coupling. Dye coupling is believed to reflect gap junctional conductance between adjacent neurons (Eghbali et al., 1990; Moreno et al., 1991), providing a means for synchronization in electrical activity and exchange of small molecules between linked cells (Bruzzone et al., 1996). As such, coupling modulates neuronal network function by increasing information flow between adjacent neurons within a given brain nucleus. Increases in dye coupling occur in the striatum after long-term manipulations of the DA system, including withdrawal from repeated antipsychotic drug administration (O’Donnell and Grace, 1995; Onn and Grace, 1995a) and after recovery from DA-depleting brain lesions (Cepeda et al., 1989; Onn and Grace, 1999). Dye coupling also can be augmented by corticostriatal activation, and this occurs via a nitric oxide-dependent mechanism (O'Donnell and Grace, 1997). Therefore, long-term alterations in the DA system that affect corticostriatal transmission appear to produce changes in dye coupling in striatal regions that persist after removal of the precipitating stimulus.

In this study, we used in vivo intracellular recording and stain- 
ing to examine the effects of acute and repeated amphetamine treatment on dye coupling in limbic cortical and striatal regions in the rat. In particular, we wanted to examine the neuronal adaptations that persisted in the drug-free condition after the withdrawal of amphetamine from the rat. Given the evidence for corticoaccumbens involvement in drug-mediated behaviors, combined with our evidence for corticostriatal modulation of dye coupling, we examined whether any alterations in dye coupling after amphetamine treatment were associated with changes in limbic cortical afferents to the accumbens and whether these changes correlate with nitric oxide synthase (NOS) activity.

Portions of these data were presented previously in abstract form (Onn and Grace, 1995b).

\section{MATERIALS AND METHODS}

Animals and drug treatment protocol. All experimental procedures were performed in accordance with the United States Public Health Service publication Guide for the Care and Use of Laboratory Animals and were approved by the Institutional Animal Care and Use Committee at the University of Pittsburgh. A total of 144 male Sprague Dawley rats, consisting of 72 vehicle-treated control rats and 72 rats treated with amphetamine, were used in this study. The control rats were treated with $0.9 \%$ saline and were subjected to treatment withdrawal in parallel with each group of the amphetamine-treated rats. One set of rats ( $n=42$ ) weighing $150-175 \mathrm{gm}$ at the start of treatment were given daily injections of amphetamine (1-3 mg/ $\mathrm{kg}$, i.p.) in their home cages for 2-4 weeks. This dosing protocol has been reported to elicit sensitization with respect to stimulant-evoked locomotor behavior in rats (Robinson and Becker, 1986; Kalivas and Duffy, 1990; Wolf et al., 1994; 1995). A second set of rats $(n=30)$ were given escalating doses of amphetamine administered at irregular intervals (i.e., 5 consecutive days alternating with a $2 \mathrm{~d}$ drug-free period over the 4 week treatment period) to more accurately simulate the abuse pattern of drug addicts (for review, see Robinson and Becker, 1986). This was done by administering amphetamine each week at an initial dose of $1 \mathrm{mg} / \mathrm{kg}$ and incrementing the dose by 0.5 $\mathrm{mg} / \mathrm{kg}$ each day to reach a final dose of $3 \mathrm{mg} / \mathrm{kg}$ on the fifth consecutive day followed by a $2 \mathrm{~d}$ washout. This regimen was repeated each week for the 4 week treatment period. Both treatment protocols have been demonstrated to lead to similar sensitization of behavioral and neurochemical responses after administration of challenge doses of amphetamine (Paulson et al., 1991; Paulson and Robinson, 1995; Wolf et al., 1995).

In vivo intracellular recording and Lucifer yellow injection. After 7-10 and 21-28 days withdrawal from amphetamine treatment, the animals were anesthetized with $8 \%$ chloral hydrate $(400 \mathrm{mg} / \mathrm{kg}$, i.p.), with supplemental anesthetic administered via a lateral tail vein catheter. In a subset of rats $(n=10)$, no withdrawal time was allowed; in this case, the animals were anesthetized $1 \mathrm{hr}$ after the last injection of amphetamine or saline. If a cell was not successfully impaled within $3 \mathrm{hr}$, an additional dose of amphetamine was administered. In vivo intracellular recordings were performed as described previously (Grace and Llinas, 1985; Onn and Grace, 1994, 1995, 1999; Onn et al., 1994a,b,c). Briefly, the recording electrodes were pulled on a Flaming-Brown p80/PC electrode puller and filled with $5-10 \%$ Lucifer yellow dissolved in $1 \mathrm{M} \mathrm{LiCl}$. The Lucifer yellow-containing microelectrodes were lowered into the PFC [coordinates: anteroposterior (AP), 3-3.5 mm anterior to bregma; mediolateral (ML), 0.5-1 mm from the sagittal suture; dorsoventral (DV), 4-6 mm from the dura] or the nucleus accumbens (coordinates: AP, $1.5-3 \mathrm{~mm}$; ML, 1-2.5 mm; DV, 5-8 mm). Cells were impaled in both control and amphetamine-treated rats based solely on their location in the PFC or nucleus accumbens. In each case, cells stained in the PFC were pyramidal-shaped neurons, and cells stained in the nucleus accumbens were of the medium spiny type. No selection was made based on their spontaneous firing pattern or activity state. Hyperpolarizing current was not applied to the cell during the initial penetration and membrane stabilization period to minimize potential artifactual labeling of cells with Lucifer yellow. After achieving stable impalement, spontaneous basal activity of the cells recorded in the PFC and in the striatal complex was collected at resting membrane potential for each neuron studied. Input resistances of the recorded and injected cells were estimated at resting membrane potential by measuring the membrane voltage deflections produced in response to $0.2-0.4 \mathrm{nA}$ hyperpolarizing current pulses (150 msec duration). Studies have shown that activation of cortical afferents can alter dye coupling in postsynaptic neurons (Hatton and Yang, 1996; O'Donnell and Grace, 1997). Therefore, stimulation of these afferents was not performed to circumvent possible secondary alterations in coupling that may occur independent of the drug treatment effects. The cells were then injected with Lucifer yellow by applying 1-3 nA constant hyperpolarizing current into the electrode interrupted by brief (5-10 msec) depolarizing pulses delivered at 4-7 Hz to prevent clogging of electrodes (Grace and Llinas, 1985; Onn and Grace, 1994, 1995, 1999; Onn et al., 1994c). Only cells with a stable resting membrane potential of at least $-60 \mathrm{mV}$ and action potential amplitudes of $\geq 55 \mathrm{mV}$ were subject to dye injection. On average, all cells scored for dye coupling in the present study were injected for at least $4 \min (7.6 \pm 3.1 \mathrm{~min} ; n=93)$. The average time of recordings was $15.1 \pm 7.2 \mathrm{~min}$, ranging from 11 to $45 \mathrm{~min}$. Electrophysiological measures and dye coupling assessments were done primarily in the 21-28 d withdrawal group. This was extended to include groups that were recorded with no withdrawal period, after 7-10 d of withdrawal, and after $14 \mathrm{~d}$ of withdrawal, to examine the time course of the observed changes, as noted under "The time course of amphetamine withdrawal-induced changes" in the Results section. The incidence of coupling was found to be similar for both the daily amphetamine treatment and the escalating treatment groups within the cortex (daily, 4 of 7; escalating, 7 of $11 ; p=1.0$ ) and the nucleus accumbens (daily, 3 of 6 ; escalating, 10 of $15 ; p=1.0)$. Therefore, the results from both groups were combined.

Staining of tissue containing Lucifer yellow-labeled cells for calbindin, tyrosine hydroxylase, and nitric oxide synthase immunoreactivity. After completion of the recordings, the deeply anesthetized rats were perfused transcardially with saline followed by $500 \mathrm{ml}$ of $4 \%$ buffered paraformaldehyde, $\mathrm{pH}$ 7.4. Serial sagittal sections ( $60 \mu \mathrm{m}$ in thickness) were cut and collected in $0.1 \mathrm{M}$ phosphate buffer. Tissue slices containing Lucifer yellow-injected cells were then examined using a Leitz Orthoplan II epifluorescence microscope equipped with the Leitz I3 filter cube (excitation: bandpass, 355-425 nm; dichromatic mirror, RKP $580 \mathrm{~nm}$; suppression: lowpass, $580 \mathrm{~nm}$ ). Dye coupling was defined as the presence of more than one labeled cell recovered after injection of a single neuron with Lucifer yellow. Only cells with complete filling of soma and dendritic processes were scored for the presence or absence of dye coupling. In the case where multiple cells were labeled from a single injection, the cells were scored as dye-coupled only if the soma and dendrites of each neuron in the cluster was completely filled. A given cluster of dyecoupled cells often spanned several sections; therefore, the total number of cells coupled after injection of a single neuron (defined as the extent of dye coupling) was determined by examining serial sections containing the entire cluster of dye-coupled neurons and dendrites. Sections containing Lucifer yellow-labeled cells were further labeled for calbindin immunoreactivity $(1000 \times$; Sigma, St. Louis, MO) using the Texas Red indirect fluorescence method as described previously (Onn and Grace, 1994, 1995, 1999; Onn et al., 1994c). Tissue containing Lucifer yellowlabeled neurons was counterstained for calbindin immunoreactivity for two purposes: (1) to distinguish the nucleus accumbens shell from the calbindin-rich core region (Onn and Grace, 1995a; Meredith et al., 1996), and (2) to limit the assessment of coupling to the PFC projection neurons that are known to be devoid of calbindin immunoreactivity (Kawaguchi, 1995). Double fluorescence-stained sections were examined using a N2 (rhodamine) filter cube (excitation: bandpass, 530-560 nm; dichromatic mirror, RKP $580 \mathrm{~nm}$; suppression: lowpass, $580 \mathrm{~nm}$ ) for Texas Red fluorescence and using a I3 filter cube for Lucifer yellow fluorescence.

Extensive lesions of the DA system in the striatum have been shown to cause an upregulation of dye coupling among medium spiny neurons (Onn and Grace, 1999). To assess whether the response to repeated amphetamine administration may have been caused in part by druginduced degeneration of the DA system, we used immunoperoxidase staining for tyrosine hydroxylase (TH) $(1000 \times$; Eugene Tech, Inc.). This stain was applied to adjacent forebrain sections or midbrain sections to assess the extent of DA terminal and cell body loss (Onn et al., 1986; Onn and Grace, 1999) in the amphetamine-treated brains. DA cell body counts were conducted on each of three $60-\mu \mathrm{m}$-thick coronal sections of the ventral tegmental area and the substantia nigra at the following AP coordinates (with respect to bregma): $-5.2 \mathrm{~mm},-5.6 \mathrm{~mm}$, and $-6.0 \mathrm{~mm}$ (Onn and Grace, 1999). Immunoreactivity for nitric oxide synthase (1500×; Sigma) was performed to examine whether changes in nitric oxide accompanied the alterations of coupling found in rats after withdrawal from repeated amphetamine administration. The number of NOS-immunoreactive cells was determined within a designated area $(1 \times 1 \mathrm{~mm})$ in both prelimbic cortex and accumbens on two sagittal 
sections at 1.4 and $2.0 \mathrm{~mm}$ lateral to the midline sagittal suture. The specificity of each antibody used in this study was tested by omitting either the primary or secondary bridging antiserum, resulting in negative staining. All immunocytochemical markers were assessed in the $14 \mathrm{~d}$ withdrawal group, with additional qualitative confirmations performed in the withdrawal groups used for electrophysiological recordings and assessment of dye coupling.

Statistics. Data were analyzed by averaging across cells, and expressed as mean $\pm \mathrm{SD}$. Differences between control and experimental groups were assessed using Student's $t$ test. A nonparametric Fisher's exact test was used to compare the incidence of dye coupling, as defined by the percentage of total dye injections that resulted in labeling of more than one cell per injection. To fulfill the requirement for independence in the Fisher's exact test, only a single cell was labeled per structure unilaterally.

\section{RESULTS}

\section{Effects of withdrawal from repeated amphetamine administration on PFC projection neurons}

\section{Vehicle-treated control rats}

A correlative analysis of the morphology and electrophysiology of single PFC neurons using Lucifer yellow-filled microelectrodes was conducted in age-matched control rats (i.e., on days 21-28 after cessation of saline injection). The neurons recorded and stained in this study exhibited resting membrane potentials of $-69.1 \pm 8.1 \mathrm{mV}$ (mean $\pm \mathrm{SD}$ ) and input resistances of $52.7 \pm$ 11.6 M $\Omega$. Approximately half of the cortical neurons recorded $(n=22)$ fired in a single-spike discharge mode (54\%; Fig. $1 A, B)$, with the remaining cells exhibiting an oscillatory, irregular firing pattern $(24 \%)$ or a burst firing pattern (22\%; Fig. $1 C)$. Fourteen percent of all cells recorded were found to exhibit spontaneous depolarization plateau potentials $(>5 \mathrm{mV}$ in amplitude) that caused the membrane potential to shift between two stable states of membrane voltages (Cowan and Wilson, 1994). The plateaus exhibited an average amplitude of $12.6 \pm 4.7 \mathrm{mV}$ and frequency of $1.3 \pm 0.5 \mathrm{~Hz}$ (Fig. $1 C$ ). Spontaneous depolarization plateau potentials were also observed as subthreshold oscillations in nonfiring neurons and were underlying spontaneous spike discharge in spontaneous firing cells (Fig. $1 C$ ).

Fifteen neurons were labeled by injection with Lucifer yellow. Thirteen of these neurons were localized to the deep layers of ventral prefrontal cortices including prelimbic $(n=4)$, infralimbic $(n=5)$, and orbital $(n=4)$ cortex; in addition, two neurons were localized to the middle layer of orbital cortex. In each case, only a single neuron was labeled. In general, these neurons exhibited numerous spiny basilar dendrites that had branching patterns ranging from sparse and polarized (Fig. $2 A, C$ ) to densely radiating (Fig. $2 E$ ) patterns. Despite the variable appearance of their somatodendritic morphology, these neurons exhibited characteristics consistent with pyramidal neurons in the PFC. Nine of these 15 labeled neurons exhibited: (1) a regular, rhythmic single spike discharge pattern at $\sim 3-5 \mathrm{~Hz},(2)$ the presence of depolarizing afterpotentials after the fast repolarization phase of the action potential, and (3) a prominent spike afterhyperpolarization (Fig. $1 A$ ). The remaining six neurons exhibited oscillatory irregular or burst firing patterns (Fig. $1 B, C$ ), with burst firing defined as the presence of spontaneously occurring doublet or triplet spikes riding on a plateau membrane depolarization. These characteristics are similar to those of cortical pyramidal projection neurons described previously (McCormick et al., 1985; Cowan and Wilson, 1994; Steriade et al., 1996; Yang et al., 1996).

In 9 of 15 of the cortical cells labeled with Lucifer yellow, the axon was traced into the ipsilateral striatal complex (Fig. 2D,F). In addition, none of the neurons stained exhibited double labeling for calbindin immunoreactivity (Fig. $2 B, C$ ), which is known to

\section{A: Non-firing PFC Cell}

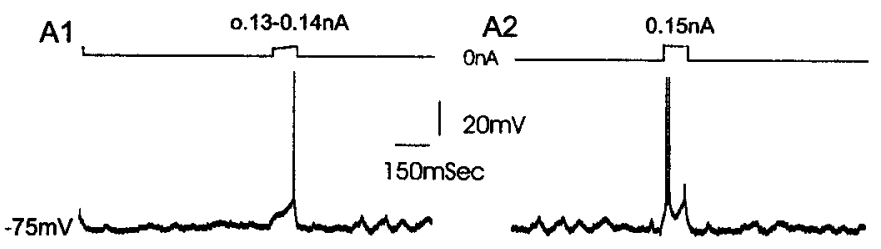

\section{B: Regular-spiking PFC Cell}
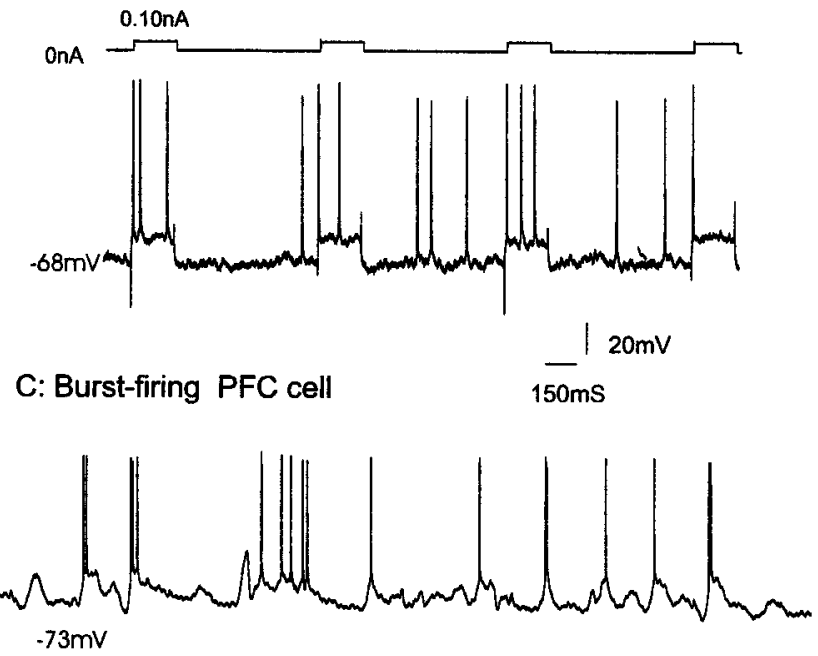

Figure 1. In vivo intracellular recording showing examples of the activity patterns of identified PFC projection neurons from vehicle-treated control rats. $A$, Recording from a nonfiring neuron in which single $(A 1)$ or doublet $(A 2)$ action potentials were triggered by current injection-induced depolarization of the membrane. $B$, Recording from a spontaneously firing neuron that exhibited predominantly a single-spike firing pattern. $C$, Recording of a burst-firing cell exhibiting clusters of three to five spikes riding on oscillatory depolarizing plateau potentials. The depolarizing potentials are typically $10-20 \mathrm{mV}$ in amplitude and occur irregularly at a frequency of $1.3 \mathrm{~Hz}$ in this case. Both regular-spiking $(A, B)$ and bursting cells $(C)$ were found to comprise a single morphological class that projects to the nucleus accumbens.

label a subclass of GABAergic interneurons in the cortex (Kawaguchi, 1995). In five of nine cases, the axon was observed to bifurcate before entering the corpus callosum along its course to the striatal complex (Fig. $2 F$ ). These morphological characteristics corresponded to the corticostriatal pyramidal neurons described recently in the prelimbic cortex (Levesque and Parent, 1998) and in the medial agranular cortex (Wilson, 1987).

\section{Amphetamine-treated rats}

The cells recorded and injected in rats that had been withdrawn from amphetamine for 21-28 d displayed resting membrane potentials of $-71.3 \pm 10.4 \mathrm{mV}(p<0.4$; NS $)$ and input resistances of $54.3 \pm 4.7 \mathrm{M} \Omega(p<0.6$; NS $)$, which were not significantly different from those recorded in vehicle-treated controls. In contrast to neurons recorded in the control animals, limbic cortical neurons recorded in amphetamine-treated rats exhibited predominantly a burst-discharge pattern (55\% firing spikes in bursts; Fig. 3 ), with $30 \%$ of the remaining neurons discharging in a singlespiking pattern and $15 \%$ that were nonfiring. In addition, neurons recorded in amphetamine-withdrawn rats exhibited a trend to- 

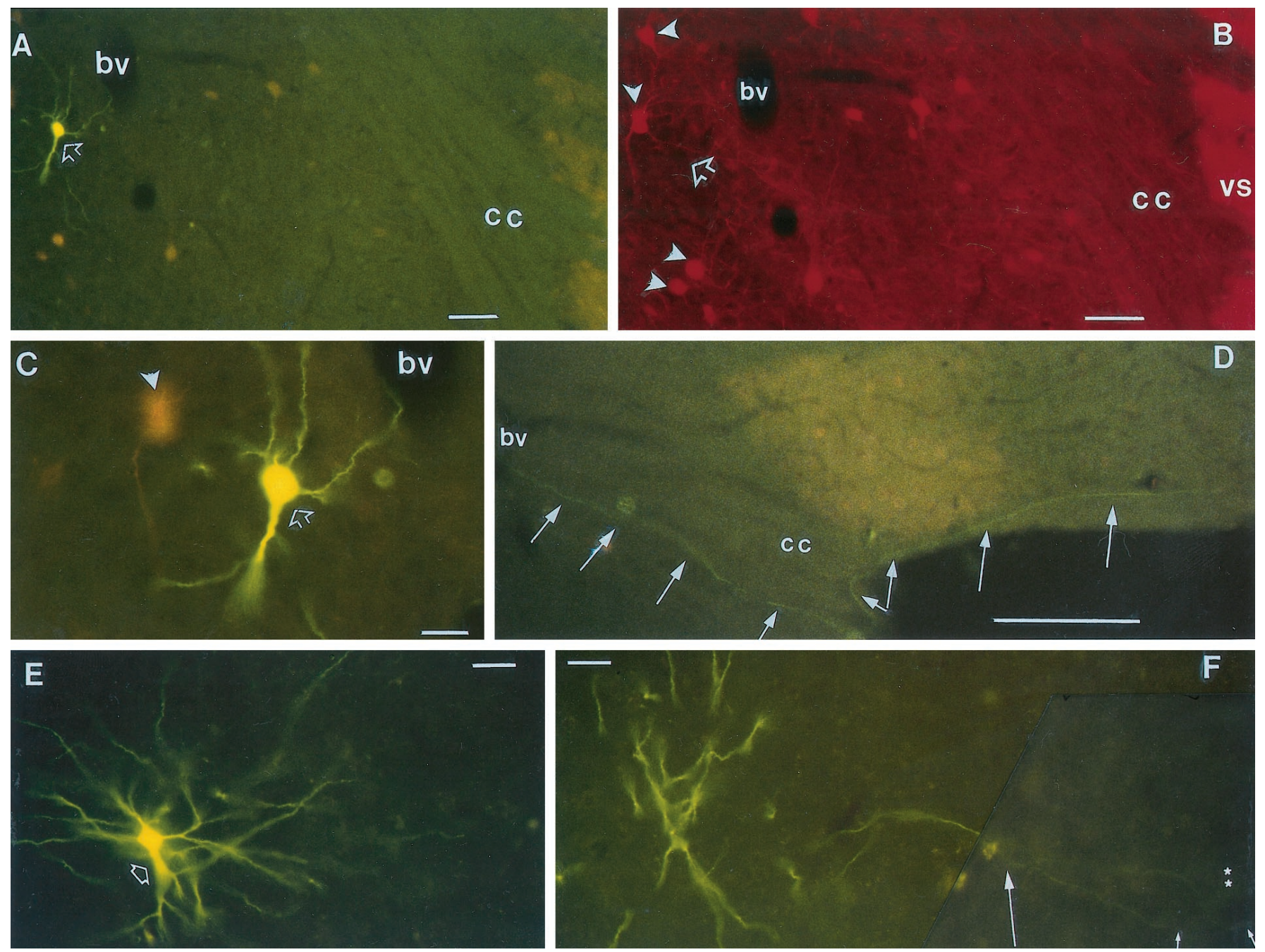

Figure 2. Photomicrographs showing Lucifer yellow-labeled PFC pyramidal neurons injected during in vivo intracellular recording from the PFC of drug-naive rats. In addition to the presence of truncated apical dendrites, the labeled cortical cells are identified as corticostriatal projection neurons based on the following features: (1) the axon of the Lucifer yellow-stained cell had a trajectory (arrows in $D$ from a section adjacent to $A$ ) that could be traced into the striatal complex, and (2) the cell ( $A$, open arrow, Lucifer yellow fluorescence) did not contain calbindin immunoreactivity that is known to stain cortical GABAergic interneurons $\left(B\right.$, arrowheads; same section showing Texas Red fluorescence for calbindin- $\left.\mathrm{D}_{28 \mathrm{k}}\right)$. Open arrow in $B$ marks the site of the Lucifer yellow-stained cell shown in $A$. $C$ (high power of $A$ ) shows numerous dendritic spines on basilar dendrites of this pyramidal projection neuron. Arrowhead indicates a pair of calbindin-positive interneurons stained by Texas Red fluorescence and examined using the Lucifer yellow filter cube. $E, F$, Another Lucifer yellow-filled PFC neuron that had a stellate-like somatodendritic morphology $(E)$ with dense dendritic branching in which the apical dendrite (E, open arrow) was not immediately apparent. Nevertheless, the axon of this cell could also be traced into the striatal complex ( $F$, arrows). The primary axon was found to branch into two equal-diameter axons before entering the corpus callosum (asterisks); only one branch is observed to enter the ipsilateral striatal complex. $b v$, Blood vessel (in $A-D$ indicating the same structure); $v s$, ventral striatum; $c c$, corpus callosum. Scale bars: $A, B, 80 \mu \mathrm{m} ; C-F, 40 \mu \mathrm{m}$.

ward elevated firing rates, although the firing frequency in the withdrawn rats was highly variable $(2.7 \pm 3.2 \mathrm{~Hz}$ vs $3.9 \pm 4.5 \mathrm{~Hz}$; $p<0.07$ ). Moreover, $40 \%$ (8 of 20) of all cortical cells recorded in amphetamine-treated rats were found to display spontaneous membrane depolarizing plateau potentials (Fig. 3B,C), as compared to $14 \%$ in controls $(p<0.05)$. These membrane oscillations were found to occur at approximately the same frequency $(1.2 \pm 0.4 \mathrm{~Hz})$ but with a larger amplitude $(17.5 \pm 3.2 \mathrm{mV})$ than those recorded in PFC neurons of vehicle-treated rats $(1.3 \pm 0.5$ $\mathrm{Hz}, \mathrm{NS}$, and $12.6 \pm 2.4 \mathrm{mV}, p<0.05$, respectively).

Of the cells recorded in amphetamine-treated rats, 18 were labeled with Lucifer yellow at the completion of the recording period. Of these, 10 exhibited a burst firing pattern, and eight were regular-spiking neurons before dye injection. Eleven of these 18 cells $(60 \%)$ injected with Lucifer yellow exhibited dye coupling, defined as the labeling of more than one cell per single cell injected (Fig. 4), presumably as a consequence of dye transfer via gap junctions (Stewart, 1978; MacVicar and Dudek, 1981; Grace and Bunney, 1983; Cepeda et al., 1989; Hatton and Micevych, 1992; O’Donnell and Grace, 1993; Peinado et al., 1993; Onn and Grace, 1994, 1995, 1999; Rorig et al., 1995; Rorig and Sutor, 1996). This represented a significantly higher incidence of coupling between PFC pyramidal cells in rats that had been withdrawn from repeated amphetamine when compared to that observed in controls ( 11 of 18 vs 0 of 15 in controls; $p=0.03$; Fisher's exact test). These eleven sets of coupled cells were located in the middle to deep layers (i.e., layers 5 and 6) of the PFC, including orbital, infralimbic, and prelimbic cortices (Fig. $4 A-C)$. Typically, axons of cells engaged in coupling failed to exhibit a substantial level of staining, possibly because of shunting 
A:

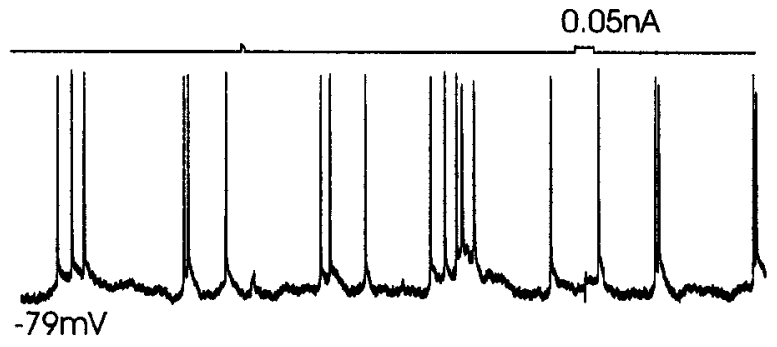

$$
\underset{100 m s}{10 m v}
$$

B:

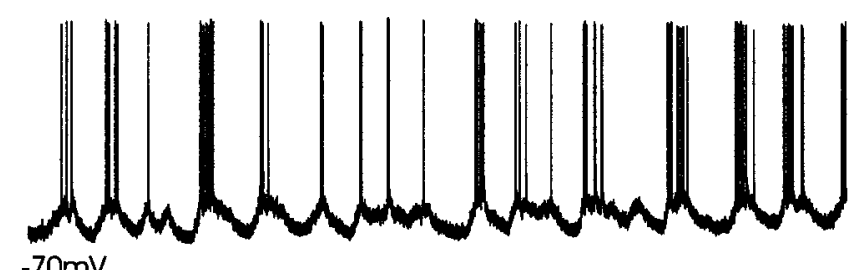

$-70 \mathrm{mV}$

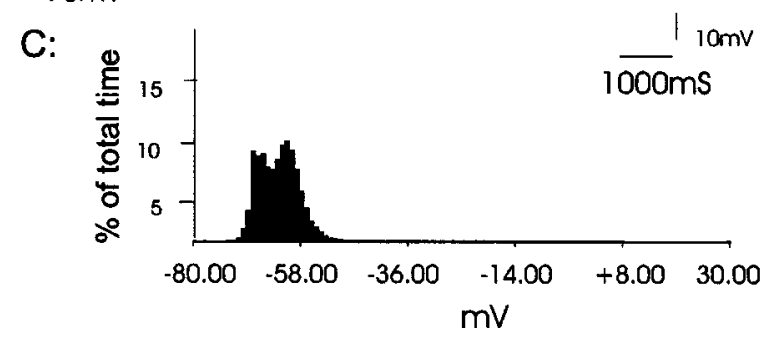

Figure 3. In vivo intracellular recording showing examples of membrane oscillations and the activity patterns of identified PFC projection neurons from amphetamine-withdrawn rats. In the withdrawn rats, limbic cortical neurons exhibited primarily a burst-discharge pattern. $A$, An example of a spontaneously burst-firing neuron identified in layer 5 infralimbic cortex in a rat after $14 \mathrm{~d}$ of withdrawal from repeated exposure to amphetamine for 4 weeks. This neuron had a resting membrane potential of $-79 \mathrm{mV}$. This neuron fired spontaneous spikes at $7 \mathrm{~Hz}$ within bursts with two to four spikes riding on membrane depolarization plateau potentials. $B$, In $\sim 40 \%$ of PFC neurons recorded in amphetamine-withdrawn rats, the cell membrane oscillated in a rhythmic manner at $\sim 1 \mathrm{~Hz}$. $C$, Histogram showing the distribution of membrane potential with respect to the percentage of time that the membrane existed at each potential. This histogram reveals the presence of two peaks, with equal time spent in the up $(-59 \mathrm{mV})$ and down $(-70 \mathrm{mV})$ states.

of dye among the coupled cells. Nevertheless, in four of the neurons that did not exhibit dye coupling, the axons could be traced into the accumbens (data not shown), which was similar to that observed in control rats (Fig. 2). As in the control cases, coupled cells did not exhibit staining for calbindin- $D_{28 \mathrm{k}}$ protein (data not shown) that is known to label a subclass of GABAergic interneurons in the cortex (Kawaguchi, 1995).

\section{Effects of withdrawal from repeated amphetamine treatment on ventral striatal spiny neurons \\ Vehicle-treated control rats}

In recordings from the ventral striatal region (i.e., ventral posterior striatum, nucleus accumbens core, and shell regions), injection of single cells with Lucifer yellow $(n=14)$ resulted in the labeling of spiny neurons, with eight located within the core (Fig. $5 A$ ) and six localized to the shell region (Fig. $5 B$ ) of the nucleus accumbens. The shell and core regions were delineated by the absence of calbindin-stained neuropil in the shell when compared with the core and other striatal regions (Onn and Grace, 1995a, 1999). Unlike those stained in the dorsal striatum (Onn and Grace, 1994, 1995; Onn et al., 1994c), reconstructions from multiple sections of spiny neurons stained in the shell region revealed smaller somatal size $(13.7 \pm 1.7$ vs $16.2 \pm 2.1 \mu \mathrm{m}$ in diameter for the spiny neurons in the core and ventral striatum, respectively; $p<0.05)$ and fewer dendritic branches $(4.3 \pm 1.6$ vs $6.2 \pm 1.0$ per cell in the core or ventral striatum, respectively; $p<0.05$ ) that tended to extend preferentially along the anteroposterior plane. Moreover, axons of spiny neurons in the shell were often observed to arise from one of the primary dendrites (Fig. 5B1) and project toward the ventral pallidum where they arborized into an extensive collateral system (Fig. 5B4,B5). Consistent with our previous observations made in vitro (O'Donnell and Grace, 1993), the accumbens core and shell neurons exhibit similar passive membrane properties. Thus, the averaged resting membrane potential in the accumbens neurons recorded and injected in control rats was $-73.1 \pm 7.4 \mathrm{mV}$. In addition, neurons in the shell exhibited higher levels of spontaneous activity $(8.7 \pm 4.2 \mathrm{~Hz} ; p<$ 0.05; Fig. 6) and a trend toward higher input resistances (57.2 \pm $15.7 \mathrm{M} \Omega ; p<0.06$; NS) when compared to spiny neurons identified in the accumbens core $(2.9 \pm 4.5 \mathrm{~Hz} ; 41.8 \pm 12.2 \mathrm{M} \Omega)$. Only $9 \%$ ( 2 of 23 cells, with nine of these cells recorded using neurobiotin-filled microelectrodes) of the spiny neurons recorded in the accumbens of control rats displayed spontaneous depolarizing plateau potentials (frequency, $0.9 \pm 0.6 \mathrm{~Hz}$; amplitude, $13.5 \pm 5.2 \mathrm{mV}$ ). This occurred independent of whether the cell was not firing (Fig. $6 \mathrm{~A}$ ) or was firing action potentials spontaneously (Fig. $6 C$ ). It should be noted that the proportion of neurons exhibiting this bistable state was substantially lower than what we had reported previously (O'Donnell and Grace, 1995). This is likely attributable to a number of factors. For example, membrane oscillations are known to be sensitive to the level of anesthesia (Leung and Yim, 1993; Wilson and Kawaguchi, 1996), and for this reason, in our previous study we used constant infusion of chloral hydrate anesthesia to keep the rats at a moderate level of anesthesia. However, because of the need to perform long-term injections of Lucifer yellow, the rats in this case were kept for several hours at a deep level of anesthesia, as monitored by the hindlimb withdrawal reflex.

Consistent with our previous observations made in vivo (Onn and Grace, 1994, 1995) and in vitro (O'Donnell and Grace, 1993), low incidences of dye coupling were found among neurons stained in the ventral striatum of control rats ( 2 of 14; Fig. 5), with two cases of coupling being identified in the accumbens core region and in the ventrolateral striatum (data not shown). Cases of dye coupling were not observed for cells injected in the accumbens shell region $(n=6)$, including the anterior sector (three of six cases; Fig. 5B). Similar low incidences of intercellular coupling were observed when single accumbens neurons were injected with neurobiotin, in that only one of nine cases resulted in the labeling of more than one cell.

\section{Amphetamine-treated rats}

The cells recorded and injected in the accumbens in rats that had been withdrawn from amphetamine exhibited an averaged resting membrane potential of $-74.7 \pm 11.7 \mathrm{mV}$, which was not significantly different from that observed in the control rats. However, after withdrawal from amphetamine, staining of neurons in the ventral striatum revealed significantly higher levels of dye coupling (controls, 2 of 14 vs withdrawal, 13 of 21; $p=0.007$; Fisher's 

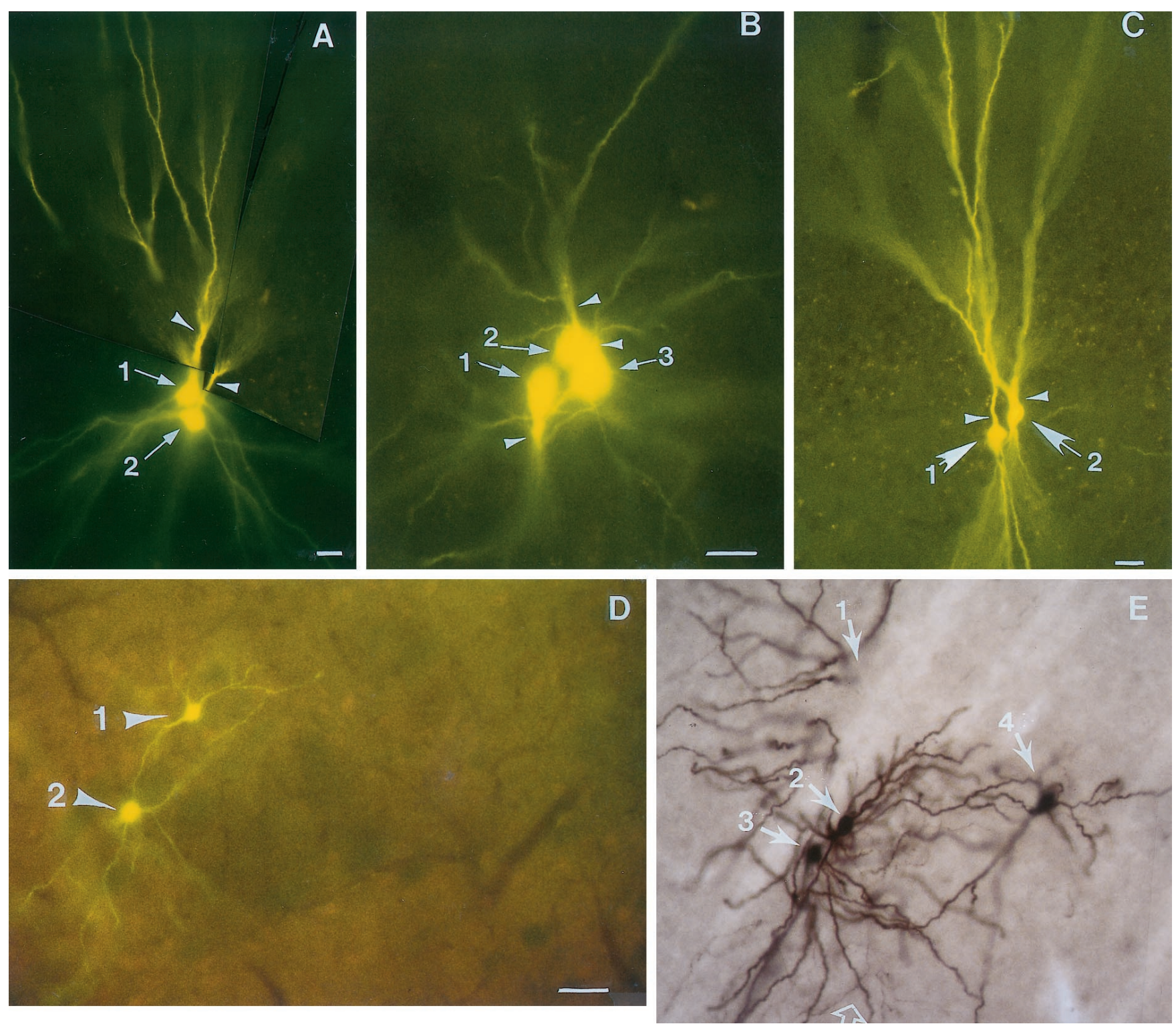

Figure 4. Photomicrographs showing examples of dye-coupled cells in the deep layer of PFC $(A-C)$ and in the ventral striatum $(D, E)$ of rats recorded 21-28 d after withdrawal from amphetamine. In each case, a single cell was injected with the dye during in vivo intracellular recording from amphetamine-withdrawn rats. Coupled cells were recovered in the prelimbic $(A)$, infralimbic $(B)$, and orbital $(C)$ cortices that exhibit properties consistent with PFC pyramidal neurons. Arrows with numbers indicate the number of cell bodies in each cluster of coupled cells, whereas the open arrows label their apical dendrites. Superficial layers in $A-C$ are toward the top of the photomicrographs. $D$, A pair of spiny neurons (arrows) in the ventrolateral striatum of an amphetamine-treated rats after injecting a single neuron. Double staining of the coupled neurons for calbindin- $\mathrm{D}_{28 \mathrm{k}}$ immunoreactivity (marked by Texas Red fluorescence) reveals that the coupled cells lie at the border of a striosome (as marked by negative neuropil staining for calbindin immunoreactivity). The background level of Texas Red fluorescence does not appear as intense because of the use of the I3 filter cube to view the Lucifer yellow fluorescence, but nevertheless still reveals the border of this striosome. E, A cluster of Lucifer yellow-labeled spiny cells (arrows) in the ventromedial striatum (at the juncture of the accumbens core region) of an amphetamine-withdrawn rat. The Lucifer yellow was subsequently converted into a peroxidase stain (brown) using antibodies to Lucifer yellow to better reveal the dendrodendritic contacts between the coupled cells. In all cases, the coupling was restricted to cells of the same morphological cell class. Open arrows mark axonal collaterals in contact with dendritic processes. The cell marked by arrow 1 was located on the adjacent section to $F$ (data not shown). Scale bars: $A-C, 30 \mu \mathrm{m} ; D, 40 \mu \mathrm{m} ; E$ is at the same scale as $D$.

exact test). Sets of coupled cells in the ventrolateral striatum were often found to cross matrix and striosome compartments, which could be distinguished by calbindin neuropil staining (Fig. 4D; Onn and Grace, 1995a, 1999). In addition to an increase in the incidence of coupling, there was also a significant increase in the extent of coupling, defined as the average number of cells labeled per injection (vehicle, 2.0 vs amphetamine, $3.4 ; p<0.01$ ). All cases of coupling that extended beyond three cells $(n=5)$ were found only in the treatment-withdrawal group and were located in the fundus of the striatum and medial posterior striatum (core region) (Fig. 4E). As observed previously, even in those cases in which injection of a single cell resulted in dye coupling among five cells, the coupling was nonetheless restricted to a single morphological cell class; i.e., medium spiny cells (Fig. 4E). Thus, repeated treatment with amphetamine resulted in an increase in both the incidence and the extent of coupling observed in the ventral striatal complex. Moreover, in amphetamine-withdrawn rats significantly higher numbers $(39 \% ; 8$ of $21 ; p=0.03$; Fisher's 


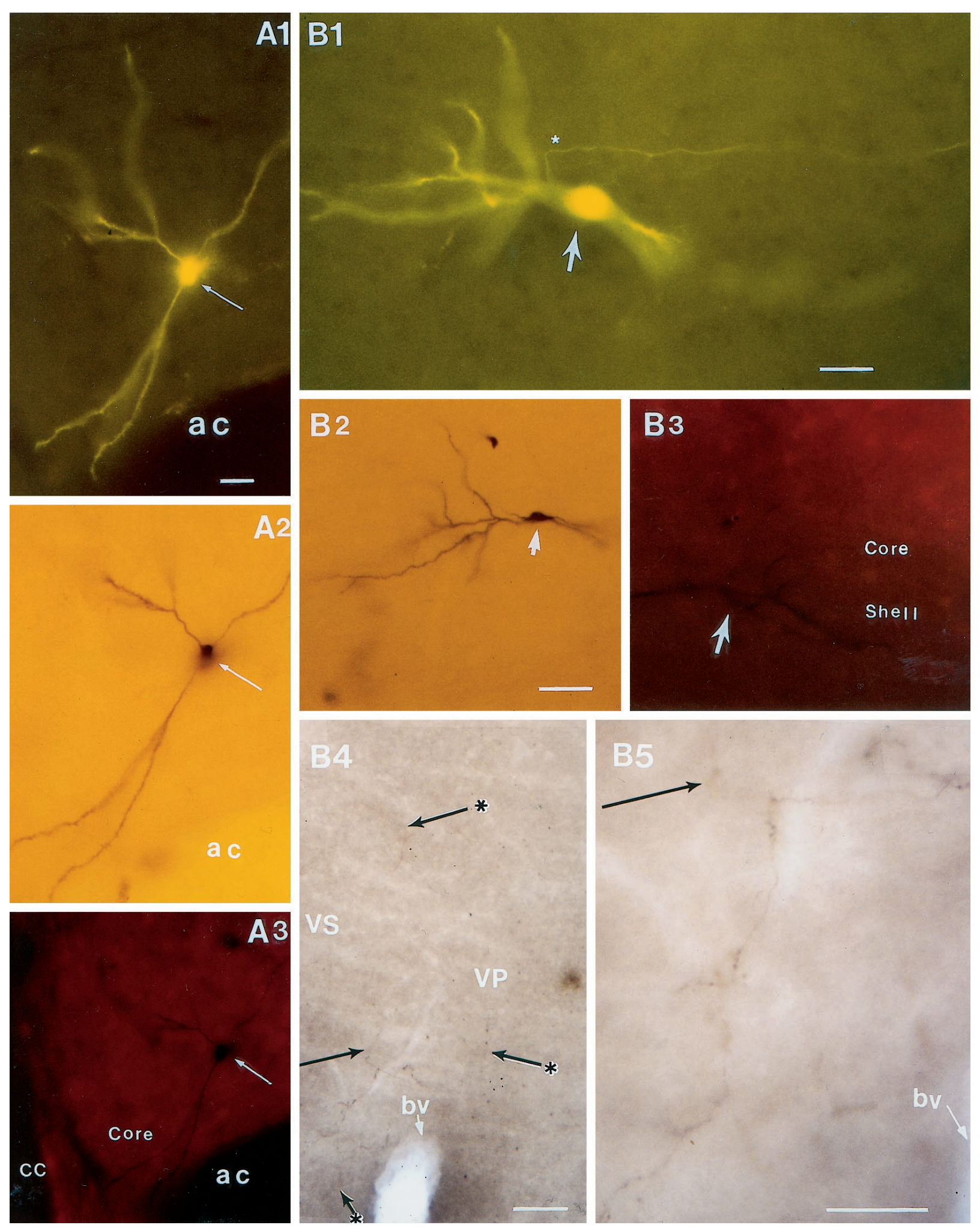

Figure 5. Photomicrographs showing Lucifer yellow-labeled spiny cells identified in the accumbens core $(A)$ and shell $(B)$ region. In control rats, most injections of individual cells with Lucifer yellow resulted in single-cell labeling of spiny neurons. $A$, A single Lucifer yellow-labeled spiny neuron (A1, arrow) that was converted into a peroxidase stain using Lucifer yellow antibodies $(A 2)$. This cell was subsequently identified in the accumbens core region ( $A 3$, arrow), as delineated by the calbindin-positive neuropil (presence of Texas Red fluorescence). Spiny neurons in the core region tended to have more widespread dendritic processes than those recovered in the shell region. B, A single Lucifer yellow-labeled spiny neuron (B1, arrow) in which the fluorescence was converted into a peroxidase stain $(B 2$, arrow). This neuron was located in the accumbens shell region as outlined by the negative staining for calbindin immunoreactivity (B3, absence of Texas Red fluorescence). The axon of this cell (B1, asterisk) was traced into the ventral pallidum where numerous collaterals were emitted (B4, low power; $B 5$, high power). The three highlighted arrows with asterisks in $B 4$ show collaterals of the primary axon. The solid arrows in $B 4$ and $B 5$ mark the same axonal collateral. $b v$, Blood vessel (in $B 4$ and $B 5$ indicating the same structure); VS, ventral striatum; $V P$, ventral pallidum; $a c$, anterior commissure; $c c$, corpus callosum. Scale bars, $30 \mu \mathrm{m}$. $A 2$ and $A 3$ are at the same scale as $A 1 ; B 3$ is at the same scale as $B 2$. 
A:
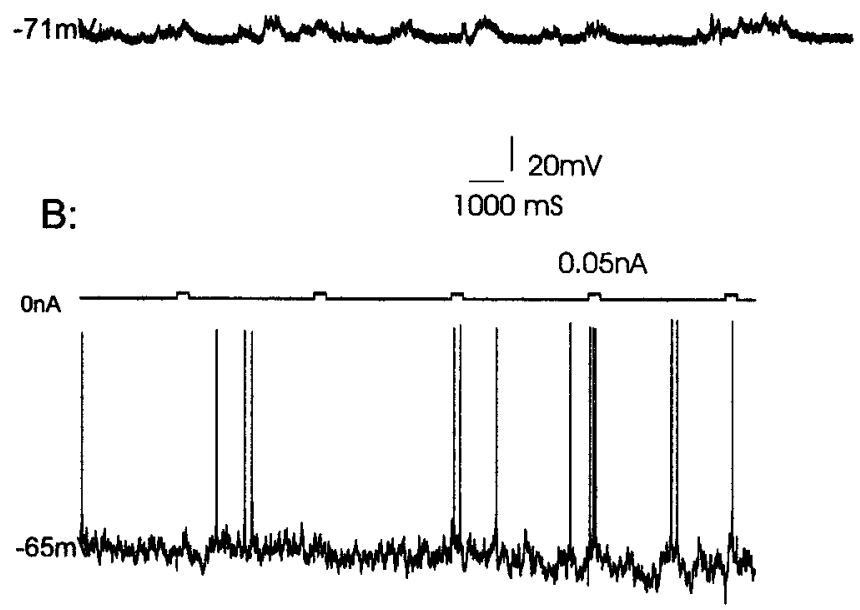

C:

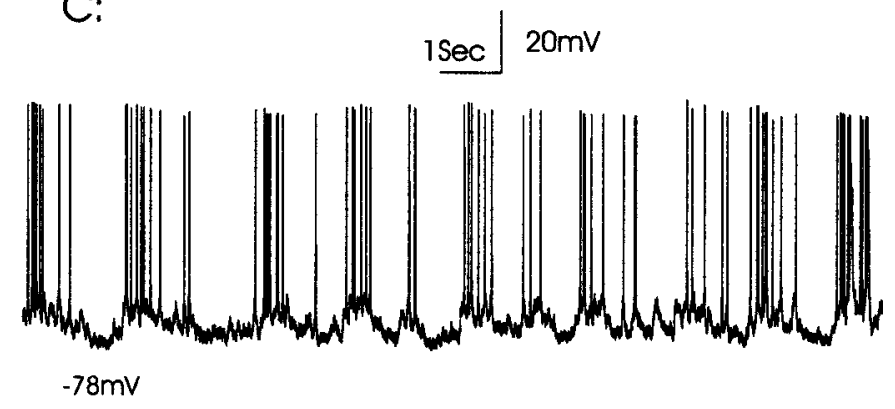

Figure 6. In vivo intracellular recordings from identified accumbens spiny neurons showing spontaneous firing activity in vehicle-treated control rats. $A$, Approximately half of the accumbens core neurons recorded in control rats are in a state of quiescence, demonstrating only subthreshold membrane depolarizations. These membrane depolarizations can occur with an oscillatory bistable $(A)$ or irregular $(B)$ pattern. $B, \mathrm{~A}$ second population of neurons exhibited low levels of spontaneous spike discharge with the spikes occurring at irregular intervals. $C$, An accumbens core spiny neuron that exhibited an oscillatory firing pattern is characterized by the occurrence of multiple spikes riding on depolarizing plateau potentials. This represents the bistable membrane potential composed of an up state at $-63 \mathrm{mV}$ and a down state at $-78 \mathrm{mV}$, respectively.

exact test) of accumbens spiny neurons were observed to display slow membrane oscillations (Fig. 7B1,B2). Both the frequency of the depolarizing events (amphetamine, $0.9 \pm 0.6 \mathrm{~Hz}$; control, $1.1 \pm 0.5 \mathrm{~Hz} ; \mathrm{NS}$ ) and their amplitude (amphetamine, $18.1 \pm 7.6$ $\mathrm{mV}$; control, $13.5 \pm 5.2 \mathrm{mV}$; NS) were not significantly different from that observed in vehicle-treated controls (Fig. 6C).

\section{Time course of amphetamine-induced changes in cellular coupling}

The observed increases in the incidence of dye coupling in both PFC and nucleus accumbens on days 21-28 after withdrawal were also found in rats on days 7-10 after withdrawal. The incidence of dye coupling observed after 7-10 d of withdrawal (accumbens, five of seven; cortex, four of seven) was not different from that observed after 21-28 d of withdrawal (accumbens, 13 of 21; cortex, 11 of 18; $p=1.0$; Fisher's exact test; NS). In contrast, in a subset of rats treated with amphetamine and recorded while the rats were still on the drug (i.e., no amphetamine-withdrawal time allowed), the level of coupling was not different from that observed in vehicle-treated control rats $(p=1.0$ for both comparisons; NS). Thus, even though each cell exhibited complete dye
A:

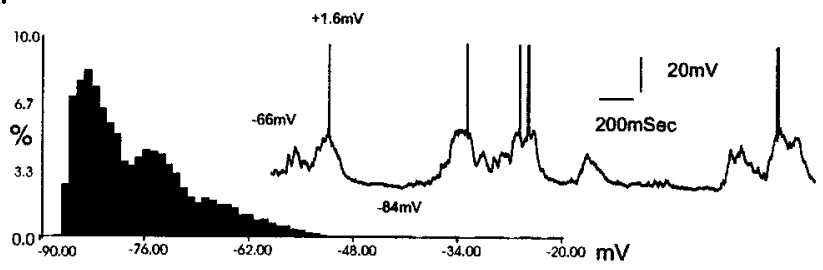

BT:

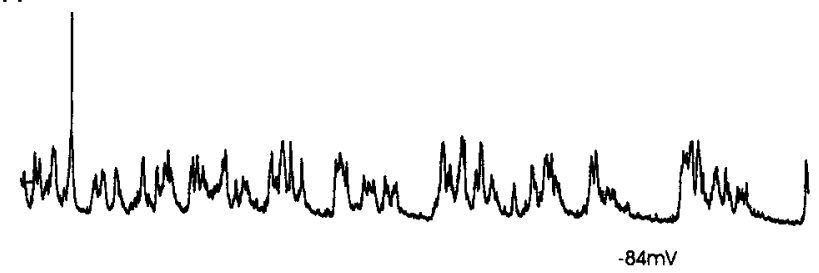

B2: 25 min later

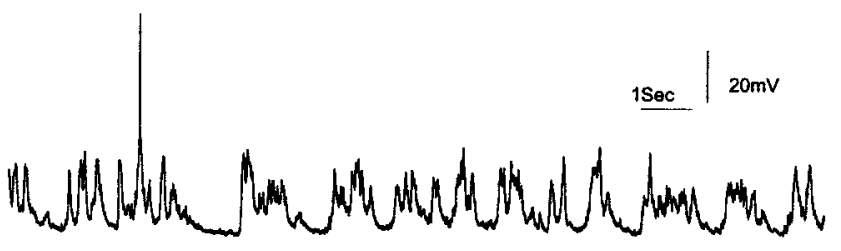

Figure 7. In amphetamine-withdrawn rats, significantly more neurons in the nucleus accumbens were found to exhibit bistable membrane potentials. $A$, Histogram showing the distribution of membrane potential with respect to the percentage of time that the membrane existed at each potential. This distribution reveals the presence of two distinct peaks, corresponding to the up $(-66 \mathrm{mV})$ and down $(-84 \mathrm{mV})$ states. In the inset, the membrane potentials corresponding to up and down states are delineated. $B$, These bistable membrane potentials are recorded for extended periods of time and are not affected by the injection of Lucifer yellow into the neuron. $B 1$, Bistable state of a neuron soon after penetration with a Lucifer yellow-containing electrode. $B 2$, The same neuron recorded 25 min later and after intracellular injection with Lucifer yellow.

filling, none of the cells injected in the PFC (zero of six) or in the nucleus accumbens (zero of five) of nonwithdrawn rats exhibited dye coupling, which was significantly different from that observed in the amphetamine-withdrawn rats $(p=0.02$ and $p=0.04$, respectively).

\section{Effects of repeated amphetamine on dopaminergic terminals in accumbens and prefrontal cortex}

Several studies have shown that prolonged treatment with amphetamine can cause destruction of DA-containing afferents to subcortical structures such as the striatum (Ellison and Switzer, 1993; Eisch and Marshall, 1998) (see also Castner and GoldmanRakic, 1999). In light of our recent finding that severe loss of DA fibers produced by injection of the neurotoxin 6-hydroxydopamine leads to an increase in intercellular coupling among striatal neurons (Onn and Grace, 1999), we examined whether there was evidence of extensive loss of catecholamine-containing afferent fibers using antibodies specific to $\mathrm{TH}$. We found no substantial alterations in $\mathrm{TH}$ immunoreactivity in the PFC and accumbens of the amphetamine-treated rats or in rats after withdrawal from amphetamine (Fig. 8B,D), although only cells stained in the latter group displayed high levels of intercellular coupling. Clearly, any amphetamine-induced damage, if present, was indiscernible from controls, especially when compared to that required for the 6-hydroxydopamine-induced increase in coupling (Onn and 

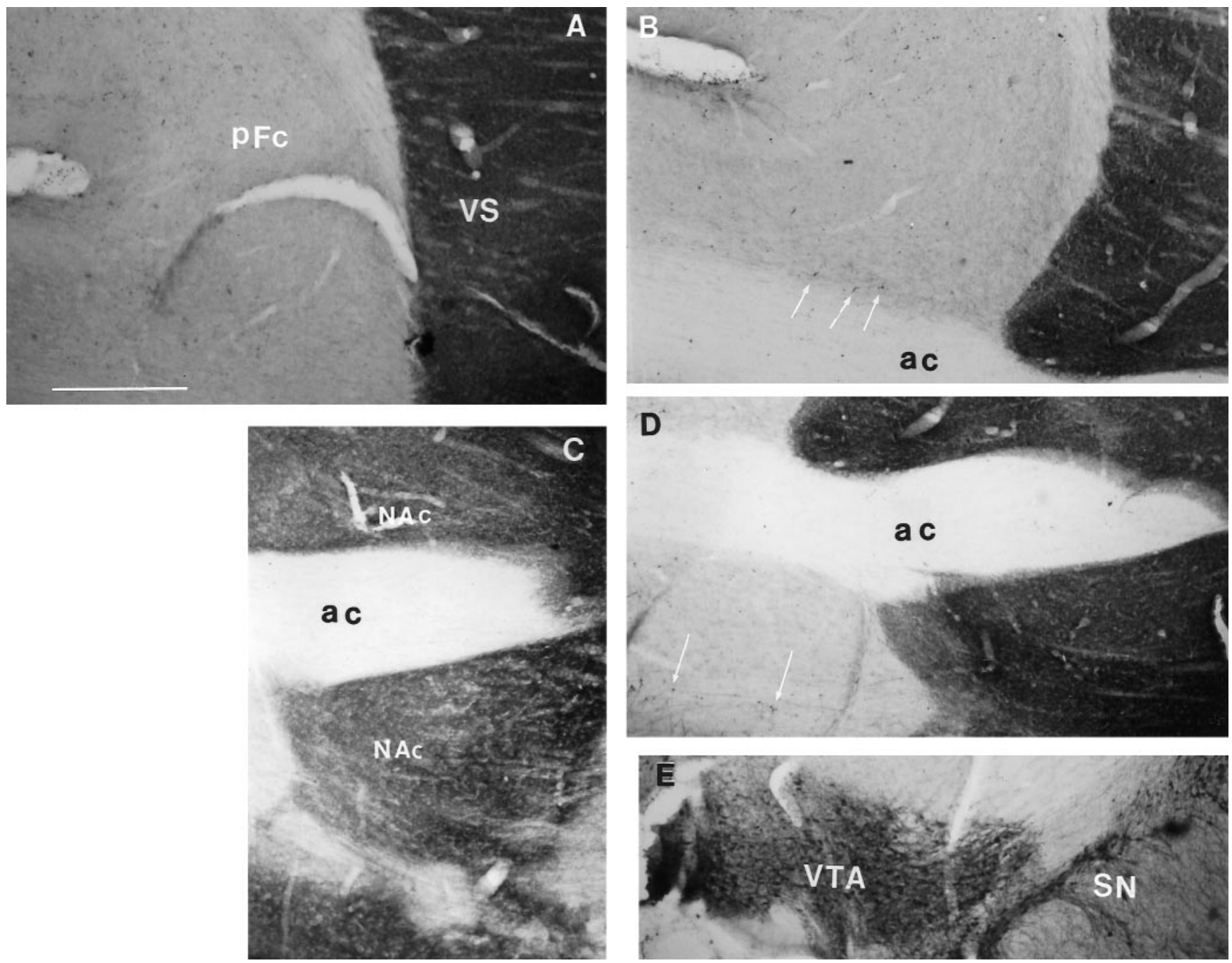

Figure 8. Photomicrographs illustrating TH immunostaining of a sagittal section containing the PFC $(A, B)$ and the nucleus accumbens $(C, D)$ in a control rat $(A, C)$ and a rat $14 \mathrm{~d}$ after withdrawal from amphetamine treatment $(B, D)$. In the PFC of the amphetamine-withdrawn rat $(B)$, the levels of TH immunoreactivity are substantially similar to that found in the control rat $(A)$. In addition, there appears to be an increase in TH staining in the cortex of amphetamine-withdrawn rats, as revealed by the presence of numerous TH-immunoreactive somata $(B, D$, arrows) that are less frequently observed in the control cortices. Similar levels of TH staining were also noted in the ventral striatum, as shown in an amphetamine-withdrawn rat ( $D$ ) when compared to a vehicle-treated control $(C)$. E, An example of TH-immunoperoxidase stain of DA cell bodies in VTA and SN, at bregma -5.6 mm. $V S$, Ventral striatum; $P F C$, prefrontal cortex; VTA, ventral tegmental area; $S N$, substantia nigra; $c c$, corpus callosum; $b v$, blood vessel. Scale bar ( in $A$ ), $200 \mu \mathrm{m}$.

Grace, 1999). Indeed, substantially high levels of TH staining were noted in the limbic cortices of amphetamine-treated rats (Fig. $8 B, D$ ), in contrast to the relatively sparse $\mathrm{TH}$ fiber staining in the control rat cortices (Fig. $8 A, C$ ). In particular, numerous $\mathrm{TH}$-immunoreactive somata were revealed in the amphetaminetreated cortices. Therefore, the amphetamine treatment paradigm used in the present study, which is known from other studies to produce sensitized behaviors (Wolf et al., 1994, 1995), did not cause any damage to the DA terminals as measured by $\mathrm{TH}$ immunoreactivity in these brain regions where high levels of intercellular coupling were observed. This observation was further confirmed by DA cell body counts in both the ventral tegmental area and substantia nigra (Fig. $8 \mathrm{E}$ ), in that similar numbers of TH- stained DA cells were observed in amphetaminetreated rats $(375 \pm 27 ; n=3)$ when compared to vehicle-treated controls (386 $\pm 34 ; n=3 ; p<0.7$;S).

\section{Decreased nitric oxide synthase immunoreactivity in PFC-accumbens systems after withdrawal from repeated amphetamine}

Several classes of GABAergic interneurons are known to be present in both cortical and subcortical regions, where they exert potent modulatory actions over the principal cell classes; i.e., the projection neurons (Bennett and Bolam, 1994; Kita, 1996). One subclass of GABAergic interneuron is reported to contain nitric oxide synthase and is known to release nitric oxide in response to NMDA receptor stimulation (Bredt and Synder, 1992). Given that nitric oxide has been reported to influence dye coupling (Hatton and Yang, 1996; Rorig and Sutor, 1996; O'Donnell and Grace, 1997), we examined whether there was an alteration in NOS immunoreactivity in rats after withdrawal from repeated amphetamine. When compared to control rats, in rats after $14 \mathrm{~d}$ of withdrawal from amphetamine treatment there was a signifi- 

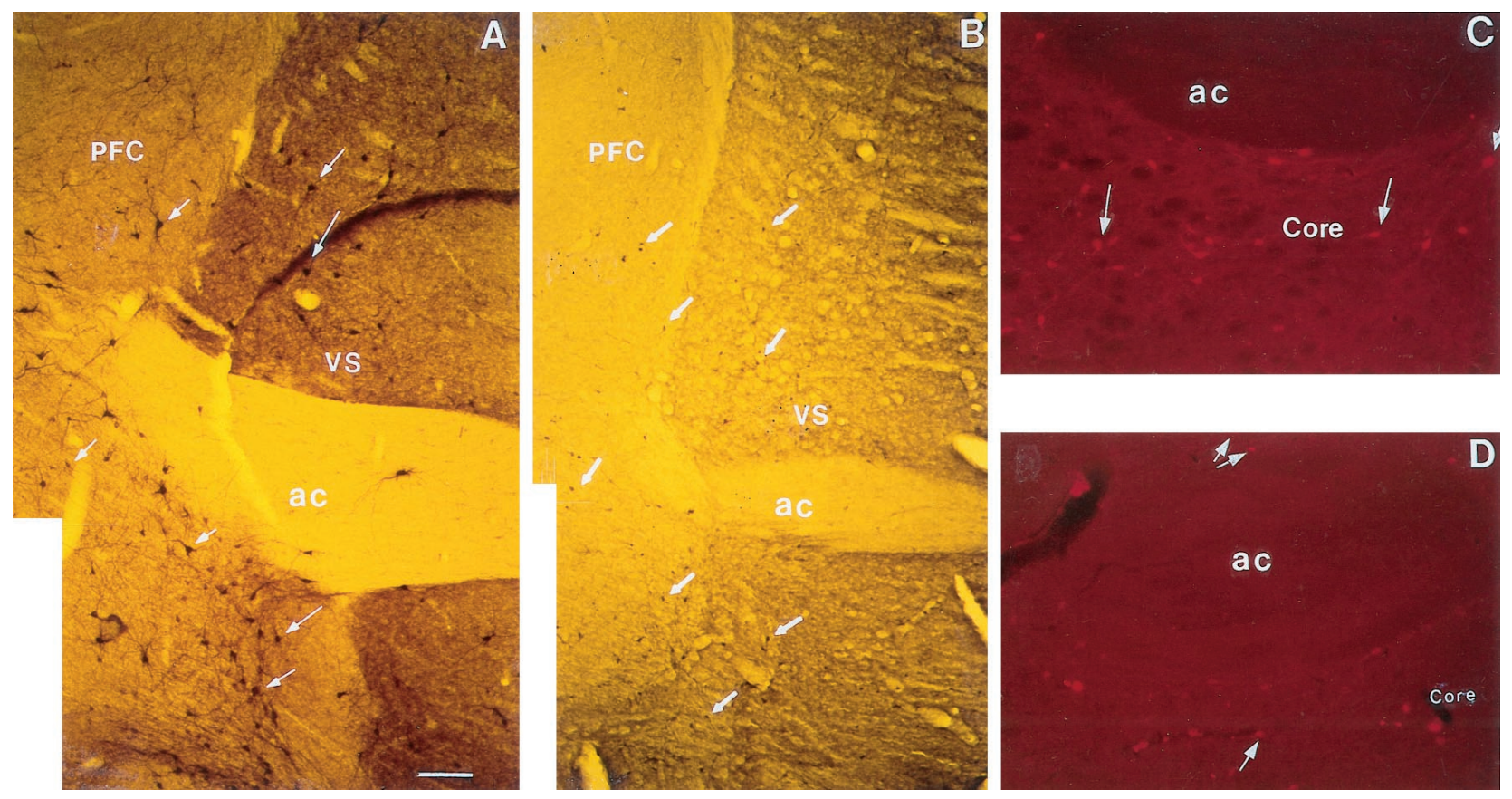

Figure 9. Photomicrographs illustrating nitric oxide synthase immunoreactivity in the $\operatorname{PFC}(A, B)$ and the nucleus accumbens $(C, D)$ in control rats $(A$, $C)$ and in rats at $14 \mathrm{~d}$ after withdrawal from amphetamine $(B, D) . A, B$, Comparisons of peroxidase-stained NOS-positive neurons in the PFC of control $(A)$ and amphetamine-withdrawn $(B)$ rats in a sagittal plane. Lower levels of NOS immunoreactivity were observed in the deep layer of PFC of amphetamine-withdrawn rats. $C, D$, Comparisons of Texas Red-labeled NOS-containing neurons in accumbens at an equivalent AP level in a coronal plane. Significantly fewer NOS-containing neurons were noted in these brain regions in amphetamine-treated rats $(D)$ as compared to those observed in paired controls ( $C$; Table 1). Arrows indicate NOS-positive neurons; PFC, prefrontal cortex; VS, ventral striatum; $a c$, anterior commissure. Scale bar (in $A$ ), $250 \mu \mathrm{m}$.

\section{Table 1. Effect of repeated administration of amphetamine on neuronal nitric oxide synthase immunoreactivity in the rat prefrontal cortex and nucleus accumbens}

Number of nitric oxide synthase-positive neurons

\begin{tabular}{lcc}
\hline & $\begin{array}{c}\text { Vehicle-treated } \\
(n=4)\end{array}$ & $\begin{array}{c}\text { Amphetamine-treated } \\
(n=4)\end{array}$ \\
Region & $209 \pm 24$ & $117 \pm 12 ;{ }^{*} p<0.05$ \\
Prefrontal cortex & $162 \pm 16$ & $54 \pm 10 ;{ }^{*} p<0.005$ \\
Nucleus accumbens &
\end{tabular}

The number of nitric oxide synthase-positive neurons was counted in 60 - $\mu$ m-thick sections in a designated area $(1 \times 1 \mathrm{~mm})$ within these brain regions (at the M-L coordinates: $1.4 \mathrm{~mm}$ and $2.0 \mathrm{~mm}$ lateral to the sagittal suture; Paxinos and Watson, $1986)$ in rats at $14 \mathrm{~d}$ after withdrawal from amphetamine. *Student's $t$ test compared to vehicle-treated control.

cant decrease in NOS immunoreactivity in the neuropil of both the PFC and nucleus accumbens (Fig. 9). This was accompanied by a significant decrease in the number of neurons displaying NOS immunoreactivity in both brain regions of the amphetamine-withdrawn group (Table 1). The decreased NOSimmunoreactive neurons and processes were also confirmed at 7 and $28 \mathrm{~d}$ of withdrawal ( $n=3$ for each time point).

\section{DISCUSSION}

Using in vivo intracellular recordings in rats after repeated amphetamine administration and withdrawal, we observed alterations in the corticoaccumbens network interactions that are persistent in nature. These included: (1) increased intercellular coupling among neurons in the PFC and nucleus accumbens, (2) increased bistable membrane activity, and (3) an apparent compensatory downregulation of NOS. In contrast, in rats that re- ceived identical amphetamine treatment but were recorded during the treatment period, none of these changes were observed. Therefore, withdrawal from amphetamine unmasked alterations in the corticoaccumbens system that reflect long-term adaptations in limbic system function.

\section{Amphetamine withdrawal alters the neurophysiology of the corticoaccumbens system}

Within the neocortex, withdrawal from amphetamine caused increases in indices of neuronal activity, including an increase in the amount of burst discharge, a larger number of neurons displaying bistable states, and an increase in intercellular coupling. The Lucifer yellow-stained neurons consisted of corticoaccumbens-projecting pyramidal neurons, given: (1) the absence of calbindin, which is a marker for interneuronal cell classes in the PFC (Kawaguchi, 1995), (2) their pyramidally shaped soma with an identifiable apical dendrite, and (3) the ability to follow their axons into the nucleus accumbens in 9 of 15 cases in control rats and 4 of 18 cases in amphetamine-withdrawn rats. These identified PFC projection neurons were both morphologically (Wilson, 1987; Yang et al., 1996; Levesque and Parent, 1998) and electrophysiologically (Cowan and Wilson, 1994) similar to pyramidal neurons identified as the corticostriatal projection neurons. Although there was a trend toward increased corticoaccumbens neuron firing rates in amphetamine-withdrawn rats, the high degree of variability after amphetamine appears to have prevented the differences from reaching statistical significance. One possible cause of this variability could be an activation of normally quiescent neurons which, because of their slow firing rates, would dilute the impact of increased firing in the spontaneously discharging population of cells (Hollerman and Grace, 1990). The increase in bursting discharge observed here is con- 
sistent with glutamate-induced activation of neuronal firing in several brain regions, including the nucleus accumbens, dorsal striatum, and PFC (Herrling et al., 1983; Cherubini et al., 1987, 1988; Cepeda et al., 1991; Hu and White, 1996). The increase in corticoaccumbens drive may also account for the observed increase in intercellular coupling, given the reported increases in intercellular coupling observed after activation of glutamatergic afferents to the supraoptic nucleus (Hatton and Yang, 1996) and striatum (O’Donnell and Grace, 1997).

In concert with the increase in neuronal activity in the PFC, we also observed an activation of neurons within the nucleus accumbens in amphetamine-withdrawn rats. This activation consisted primarily of an increase in the proportion of accumbens neurons exhibiting bistable membrane oscillations, which is a characteristic of these neurons (Yim and Morgenson, 1988; O'Donnell and Grace, 1995). At least a part of the increase in membrane oscillations may be attributable to the depolarization produced by enhanced excitatory transmission from corticoaccumbens afferents. We also have shown previously that the membrane depolarizing plateaus ("up state") of accumbens neurons were derived from afferents originating within the fornix, presumably representing hippocampal subiculum neuronal activity (O'Donnell and Grace, 1995). Therefore, an increase in hippocampal drive would be expected to augment oscillatory activity within the accumbens. Given the presence of reciprocal connections between the PFC and hippocampal formation (Jay et al., 1992; Carr and Sesack, 1996), an increase in hippocampal drive may also account for the enhanced oscillatory membrane activity in the PFC.

\section{Amphetamine withdrawal alters intercellular coupling and network interactions in the corticoaccumbens system}

After withdrawal from repeated amphetamine, PFC and accumbens spiny neurons exhibited high levels of intercellular coupling. Indeed, others have shown that chronic cocaine administration will induce changes in connexin expression in the accumbens and persistent increases in connexin 32 immunoreactivity in hippocampal CA1 neurons (Bennett et al., 1999). Although our previous studies showed that long-term increases in coupling can occur in vivo in adult striatal neurons after severe DA depletions by the neurotoxin 6-hydroxydopamine (Onn and Grace, 1999), DA depletion was not likely to contribute to the changes observed after amphetamine withdrawal. Given that there was no evidence for a decrease in TH-immunolabeled DA-containing cells in the ventral tegmental area (VTA) or fibers in these forebrain areas in the amphetamine-treated rats when compared to the vehicle-treated paired controls, the increased incidence of coupling in amphetamine-withdrawn rats was not a consequence of amphetamine-induced DA terminal neurotoxicity (Ellison and Switzer, 1993; Eisch and Marshall, 1998). Nonetheless, several studies have shown that disruption of DA transmission can result in marked changes in coupling in the striatum (Cepeda et al., 1989; Onn and Grace, 1999). Therefore, it is possible that a dampening in DA transmission (Robertson et al., 1991; Segal and Kuczenski, 1992; Paulson and Robinson, 1995) was a factor in the activation of coupling in amphetaminewithdrawn rats. This hypothesis is consistent with several studies showing a reduction in DA release after psychostimulant withdrawal (Acquas et al., 1991; Robertson et al., 1991; Segal and Kuczenski, 1992). The amphetamine withdrawal-induced enhancement of corticoaccumbens activity (Keys et al., 1998; Robinson and Kolb, 1998) and striatal glutamate release (Smith et al.,
1995; Reid et al., 1997; Rawls and McGinty, 1998) may play a role in this response. A compromised DA system may activate corticostriatal transmission through at least two mechanisms: (1) an increase in activity within the cortical neurons projecting to striatal/accumbens sites, as demonstrated in the present study and/or (2) a decreased DA inhibition of corticostriatal fibers (Calabresi et al., 1988; O’Donnell and Grace, 1994; Levine et al., 1996; Nicola et al., 1996; Onn and Grace, 1998). Therefore, a common mechanism of treatment-induced alteration in coupling may be the activation of corticostriatal glutamatergic transmission.

Withdrawal from amphetamine treatment also resulted in a decrease in the number of neurons exhibiting NOS staining in the accumbens of amphetamine-withdrawn rats. Glutamate is known to elicit nitric oxide release in the striatum via stimulation of NOS-containing interneurons (Bredt and Synder, 1992). This modulation of coupling by NO has also been shown to occur in several brain regions, e.g., cortex (Rorig and Sutor, 1996), hypothalamus (Hatton and Yang, 1996; Yang and Hatton, 1999), and nucleus accumbens (O’Donnell and Grace, 1997). However, the mechanism underlying this NOS downregulation is not clear. One possibility is that the decrease in NOS is a compensatory change in response to the heightened drive by the cortex, to keep the level of coupling in the nucleus accumbens in balance. Alternatively, if there is an alteration in gap junction connexin composition (Bennett et al., 1999) or in their phosphorylation state (Matsumoto et al., 1991; Kwak et al., 1995) after amphetamine, the connexins may show a heightened sensitivity to NOS. Thus, in one scenario, during amphetamine treatment there could be a downregulation of corticoaccumbens activity, necessitating an alteration in the connexins to maintain coupling at a "normal" level. Consequently, the activation of corticoaccumbens drive after amphetamine withdrawal may induce a compensatory downregulation in NOS. Thus, it is apparent that, at least with respect to dye coupling, the compensatory processes that occur after withdrawal are insufficient to restore the system to normal.

\section{Implications of amphetamine withdrawal-induced changes in the corticoaccumbens system to drug abuse}

We have shown that there are several alterations in the physiology of the corticoaccumbens system that persist for at least $28 \mathrm{~d}$ after amphetamine withdrawal. A number of studies have shown persistent changes in the forebrain after withdrawal from repeated psychostimulants (Kamata and Rebec, 1983; Koob and Bloom, 1988; Henry and White, 1991, 1995; Paulson et al., 1991; Grace, 1995; White et al., 1995; Kuhar and Pilotte, 1996; Keys et al., 1998; Robinson and Kolb, 1998; Bennett et al., 1999). However, the mechanism underlying these persistent changes is not understood. One possibility may be related to the homeostatic compensations that take place in this system during amphetamine treatment and withdrawal. Thus, during psychostimulant administration, there is evidence for an alteration in connexin content of gap junctions within limbic regions (Bennett et al., 1999). Given that the alteration in dye coupling is not observed until after amphetamine is withdrawn, it appears that the change in connexin may be part of a compensatory process to maintain coupling at a normal state during amphetamine treatment. After amphetamine withdrawal, there is in addition another alteration layered into the system; i.e., a decrease in NOS-positive neurons in the PFC and nucleus accumbens. One possibility is that this is the means by which the system compensates for the alterations in gap junction composi- 
tion, because a return of the gap junctions to their original configuration may require substantial amounts of time to occur. The consequence of these multiple layers of adaptation is that the amphetamine-withdrawn system is now in a new steady-state, because the compensatory changes produced by amphetamine withdrawal do not return the system to the pre-amphetamine state (Grace, 1995). Such a condition may be similar to those adaptive cellular processes that occur in association with each phase of drug addiction as advanced by our laboratory (Grace, 1995) and by others (Koob, 1992; Bonei and Williams, 1996; Nestler and Aghajanian, 1997). Therefore, repeated amphetamine administration may drive the system into a state from which it cannot return.

What is the consequence of these alterations? One possibility is that the increase in coupling may be responsible for the observed synchrony in responses reported to occur in accumbens neurons in self-administering rats after repeated exposure to psychostimulants (Peoples et al., 1998). Moreover, at a functional level, in studies using the gap junction inhibitor carbenoxolone, we found that inhibition of gap junctions blocked the stereotyped motor behavior elicited by apomorphine in the dorsal striatum (Grace and Moore, 1996), possibly by reversing the apomorphineinduced increase in dye coupling in this region (Onn and Grace, 1994). Although speculative, one possibility is that increased intercellular communication in the ventral striatum may lead to a type of limbic perseveration, such as the persistent drug-seeking behavioral patterns demonstrated by drug addicts even after long-term drug abstinence (Robinson and Berridge, 1993). Such a process could be related to the permanent changes that occur in the brains of drug addicts (Kuhar and Pilotte, 1996; Gatley and Volkow, 1998) that cause them to persist in drug-seeking behavior and make them prone to relapse.

\section{REFERENCES}

Acquas E, Carboni E, DiChiara G (1991) Profound depression of mesolimbic dopamine release after morphine withdrawal in dependent rats. Eur J Pharmacol 193:133-134.

Berger B (1992) Dopaminergic innervation of the frontal cerebral cortex. Evolutionary trends and functional implications. Adv Neurol 57:525-544.

Bennett BD, Bolam JP (1994) Synaptic input and output of parvalbumin-immunoreactive neurons in the neostriatum of the rat. Neuroscience 62:707-719.

Bennett SAL, Arnold JM, Chen J, Stenger J, Paul DL, Roberts DCS (1999) Long-term changes in connexin 32 gap junction protein and mRNA expression following cocaine self-administration in rats. Eur J Neurosci 11:3329-3338.

Bonei A, Williams JT (1996) A common mechanism mediated long-term changes in synaptic transmission after chronic cocaine and morphine. Neuron 16:631-639.

Bredt DS, Snyder SH (1992) Nitric oxide, a novel neuronal messenger. Neuron 8:3-11.

Bruzzone R, White TW, Paul DL (1996) Connections with connexins: the molecular basis of direct intercellular signaling. Eur $\mathrm{J}$ Biochem 238:1-27.

Calabresi P, Benedetti M, Mercuri NB, Bernardi G (1988) Endogenous dopamine and dopaminergic agonists modulate synaptic excitation in neostriatum: intracellular studies from naive and catecholaminedepleting rats. Neuroscience 27:145-157.

Carr DB, Sesack SR (1996) Hippocampal afferents to the rat prefrontal cortex: synaptic targets and relation to dopamine terminals. J Comp Neurol 369:1-15.

Castner SA, Goldman-Rakic PS (1999) Long-lasting psychotomimetic consequences of repeated low-dose amphetamine exposure in rhesus monkeys. Neuropsychopharmacology 20:10-28.

Cepeda C, Walsh JP, Hull CD, Buchwald NA, Levine MS (1989) Dyecoupling in the neostriatum of the rat. I. Modulation by dopamine depleting lesions. Synapse 4:229-237.
Cepeda C, Peacock W, Levine MS, Buchwald NA (1991) Iontophoretic application of NMDA produces different types of excitatory responses in developing human cortex and caudate neurons. Neurosci Lett 126:167-171.

Cherubini E, Herrling, PL, Lanfumey L, Stanzione P (1987) Excitatory amino acids in synaptic excitation of rat striatal neurons in vitro. J Physiol (Lond) 339:207-222.

Childress AR, Mozley PD, Mcelgin W, Fitzgerald J, Reivich M, O'Brien CP (1999) Limbic activation during cue-induced cocaine craving. Am J Psychiatry 156:11-18.

Cowan RL, Wilson CJ (1994) Spontaneous firing patterns and axonal projections of single corticostriatal neurons in the rat medial agranular cortex. J Neurophysiol 71:17-32.

Eghbali B, Kessler JA, Spray DC (1990) Expression of gap junction channels in communication-incompetent cells after stable transfection with cDNA encoding connexin 32. Proc Natl Acad Sci USA 87:1328-1331.

Eisch AJ, Marshall JF (1998) Methamphetamine neurotoxicity: dissociation of striatal dopamine terminal damage from parietal cortical cell body injury. Synapse 30:433-44.

Ellison G, Switzer III RC (1993) Dissimilar patterns of degeneration in brain following four different addictive stimulants. NeuroReport $5: 17-20$.

Fuxe K, Hokfelt T, Johnasson O, Jonsson G, Ljungdahl A (1974) The origin of the dopamine nerve terminals in limbic and frontal cortex. Evidence for meso-cortical dopamine neurons. Brain Res 82:349-355.

Gatley SJ, Volkow ND (1998) Addiction and imaging of the living human brain. Drug Alcohol Depend 51:97-108.

Grace AA (1995) The tonic/phasic model of dopamine system regulation: its relevance for understanding how stimulant abuse can alter basal ganglia function. Drug Alcohol Depend 37:111-129.

Grace AA, Bunney BS (1983) Intracellular and extracellular electrophysiology of nigral dopamine neurons. 3. Evidence for electrotonic coupling. Neuroscience 10:333-348.

Grace AA, Llinas R (1985) Dehydration-induced morphological artifacts in intracellularly stained neurons: circumvention using rapid DMSO clearing. Neuroscience 16:461-475.

Grace AA, Moore H (1996) Gap junction inactivation in the striatum prevents oral stereotypy induced by apomorphine. Soc Neurosci Abstr 22:405.

Grant S, London ED, Newlin DB, Villemagne VL, Liu X, Contoreggi C, Phillips RL, Kimes AS, Margolina A (1996) Activation of memory circuits during cue-elicited cocaine craving. Proc Natl Acad Sci USA 93:12040-12045.

Hatton GI, Micevych PE (1992) Connexin 32 mRNA levels in the supraoptic nucleus prior to and during lactation. Soc Neurosci Abstr 18:417.

Hatton GI, Yang QZ (1996) Activation of excitatory amino acid inputs to supraoptic neurons: 1. Induced increases in dye-coupling in lactating but not virgin or male rats. Brain Res 513:264-269.

Henry DJ, White FJ (1991) Repeated cocaine administration causes persistent enhancement of D1dopamine receptor sensitivity within the rat nucleus accumbens. J Pharmacol Exp Ther 258:882-890.

Henry DJ, White FJ (1995) The persistence of behavioral sensitization to cocaine parallels enhanced inhibition of nucleus accumbens neurons. J Neurosci 15:6287-6290.

Herrling PL, Morris R, Salt TE (1983) Effects of excitatory amino acids and their antagonists on membrane and action potentials of cat caudate neurons. J Physiol (Lond) 339:207-222.

Hollerman JR, Grace AA (1990) The effects of dopamine-depleting brain lesions on the electrophysiological activity of rat substantia nigra dopamine neurons. Brain Res 533:203-212.

Hu X-T, White FJ (1996) Glutamate receptor regulation of rat nucleus accumbens neurons in vivo. Synapse 23:208-218.

Jay TM, Thierry A-M, Wiklund L, Glowinski J (1992) Excitatory amino acid pathway from the hippocampus to the prefrontal cortex. Contribution of AMPA receptors in hippocampo-prefrontal cortex transmission. Eur J Neurosci 4:1285-1295.

Jentsch JD, Taylor JR (1999) Impulsivity resulting from frontostriatal dysfunction in drug abuse: implications for the control of behavior by reward-related behaviors. Psychopharmacology 146:373-390.

Kalivas PW, Duffy P (1990) Effect of acute and daily cocaine treatment on extracellular dopamine in the nucleus accumbens. Synapse 5:48-58.

Kalivas PW, Stewart J (1991) Dopamine transmission in the initiation 
and expression of drug- and stress-induced sensitization of motor activity. Brain Res Rev 16:223-244.

Kamata K, Rebec GV (1983) Dopaminergic and neostriatal neurons: dose-dependent changes in sensitivity to amphetamine following longterm treatment. Neuropharmacology 22:1377-1386.

Kawaguchi Y (1995) Physiological subgroups of nonpyramidal cells with specific physiological and morphological characteristics in rat frontal cortex. J Neurophysiol 69:416-431.

Keys AS, Mark GP, Emre N, Meshul CK (1998) Reduced glutamate immunolabeling in the nucleus accumbens following extended withdrawal from self-administered cocaine. Synapse 30:393-401.

Kita H (1996) Glutamatergic and GABAergic postsynaptic responses of striatal spiny neurons to intrastriatal and cortical stimulation recorded in slice preparations. Neuroscience 70:925-940.

Koob GF (1992) Drug of abuse: anatomy, pharmacology and function of reward pathways. Trends Pharmacol Sci 13:177-184.

Koob GF, Bloom FE (1988) Cellular and molecular mechanisms of drug dependence. Science 242:715-723.

Kuhar MJ, Pilotte NS (1996) Neurochemical changes in cocaine withdrawal. Trends Phamacol Sci 17:260-264.

Kuhar MJ, Boja MC, Ra JW (1991) The dopamine hypothesis of reinforcing properties of cocaine. Trends Neurosci 14:299-302.

Kwak BR, Hermans MM, DeJong HR, Lohmann SM, Jongsma HJ, Chanson M (1995) Differential regulation of distinct types of gap junction channels by similar phosphorylating conditions. Mol Biol Cell 6:1707-1719.

Levine MS, Li Z, Cepeda C, Cromwell HC, Altemus KL (1996) Neuromodulatory actions of dopamine on synaptically-evoked neostriatal responses in slices. Synapse 24:65-78.

Leung LS, Yim CYC (1993) Rhythmic delta-frequency activities in the nucleus accumbens of anesthetized freely moving rats. Can J Physiol Pharmacol 71:311-320.

Levesque M, Parent A (1998) Axonal arborization of corticostriatal and corticothalamic fibers arising from prelimbic cortex in the rat. Cereb Cortex 8:602-613.

Maas LC, Lucka SE, Kaufman MJ, Weiss RD, Daniels SL, Rogers VW, Kukes RJ, Renshaw PF (1998) Functional magnetic resonance imaging of human brain activation during cue-induced cocaine craving. Am J Psychiatry 155:124-126.

MacVicar BA, Dudek FE (1981) Electrotonic coupling between pyramidal cells: a direct demonstration in rat hippocampal slices. Science 213:782-785.

Matsumoto A, Arai Y, Urano A, Hyodo S (1991) Cellular localization of gap junction mRNA in the neonatal rat brain. Neurosci Lett $124: 225-228$

McCormick DA, Connors BW, Lighthall JW, Prince DA (1985) Comparative electrophysiology of pyramidal and sparsely spiny stellate neurons of the neocortex. J Neurophysiol 54:782-806.

Meredith GE, Pattiselano A, Groenewegen HJ, Haber SN (1996) Shell and core in monkey and human nucleus accumbens identified with antibodies to calbindin- $\mathrm{D}_{28 \mathrm{k}}$. J Comp Neurol 365:628-639.

Moreno AP, Eghbali B, Spray DC (1991) Connexin 32 gap junction channels in stably transfected cells: unitary conductance. Biophys $\mathrm{J}$ 60:1254-1266.

Nestler EJ, Aghajanian GK (1997) Molecular and cellular basis of addiction. Science 278:58-63.

Nicola SM, Kombian SB, Malenka RC (1996) Psychostimulants depress excitatory synaptic transmission in the nucleus accumbens via presynaptic D1-like dopamine receptors. J Neurosci 16:1591-1604.

O'Donnell P, Grace AA (1993) Dopaminergic modulation of dye coupling between neurons in the core and shell regions of the nucleus accumbens. J Neurosci 13:3456-3471.

O'Donnell P, Grace AA (1994) Tonic D2-mediated attenuation of cortical excitation in nucleus accumbens recorded in vitro. Brain Res 634:105-112.

O'Donnell P, Grace AA (1995) Synaptic interactions among excitatory afferents to nucleus accumbens neurons: hippocampal gating of prefrontal cortical input. J Neurosci 15:3622-3639.

O’Donnell P, Grace AA (1997) Cortical afferents modulate striatal gap junction permeability via nitric oxide. Neuroscience 76:1-5.

Onn S-P, Grace AA (1994) Dye coupling between rat striatal neurons recorded in vivo: compartmental organization and modulation by dopamine. J Neurophysiol 71:1917-1934.

Onn S-P, Grace AA (1995a) Repeated treatment with haloperidol and clozapine exerts differential effects on dye coupling between neurons in subregions of striatum and nucleus accumbens. J Neurosci 15:7024-703.

Onn S-P, Grace AA (1995b) Repeated amphetamine administration enhances electrotonic transmission in limbic cortical and striatal regions. The Fifth International Congress on Schizophrenia Research 15:183.

Onn S-P, Grace AA (1999) Alterations in electrophysiological activity and dye coupling of striatal spiny and aspiny neurons in dopaminedenervated rat striatum recorded in vivo. Synapse 31:1-15.

Onn S-P, Berger TW, Stricker EM, Zigmond MJ (1986) Effects of intraventricular 6- hydroxydopamine on the dopamine innervation of striatum: Histochemical and neurochemical analysis. Brain Res 376:8-19.

Onn S-P, Berger TW, Grace A A (1994a) Identification and characterization of striatal cell subtypes using in vivo intracellular recording in rats. I. Basic physiology and response patterns to corticostriatal fiber stimulation. Synapse 16:161-180.

Onn S-P, Berger TW, Grace AA (1994b) Identification and characterization of striatal cell subtypes using in vivo intracellular recording in rats. II membrane factors underlying paired pulse response profiles. Synapse 16:195-210.

Onn S-P, Berger TW, Grace AA (1994c) Identification and characterization of striatal cell subtypes using in vivo intracellular recording in rats. III. Morphological correlates and compartmental organization. Synapse 16:231-254.

Onn S-P, Skaggs WE, Grace AA (1998) Dopamine enhances limbic afferent input to prefrontal cortex while suppressing cortical throughput in nucleus accumbens. Soc Neurosci Abstr 24:655.

Paulson PE, Robinson TE (1995) Amphetamine-induced timedependent sensitization of dopamine neurotransmission in the dorsal and ventral striatum: a microdialysis study in behaving rats. Synapse 19:56-65.

Paulson PE, Camp DM, Robinson TE (1991) The time course of transient behavioral depression and persistent behavioral sensitization in relation to regional brain monoamine concentrations during amphetamine withdrawal in rats. Psychopharmacology 103:480-492.

Peinado A, Yuste R, Katz LC (1993) Extensive dye coupling between rat neocortical neurons during the period of circuit formation. Neuron 10:103-114

Peoples LL, Gee F, Bibi R, West MO (1998) Phasic firing time locked to cocaine self-infusion and locomotion: dissociable firing patterns of single nucleus accumbens neurons in rats. J Neurosci 18:7588-7598.

Prasad BM, Hochstatter T, Sorg BA (1999) Expression of cocaine sensitization: regulation by the medial prefrontal cortex. Neuroscience 88:765-774.

Rawls SM, McGinty JF (1998) Delta opioid antagonist, naltrindole, decreases amphetamine-evoked glutamate and dopamine levels in rat striatum. Soc Neurosci Abstr 24:993.

Reid MS, Hsu Jr K, Berger SP (1997) Cocaine and amphetamine preferentially stimulate glutamate release in the limbic system: studies on the involvement of dopamine. Synapse 27:95-105.

Ritz MC, Lamb RJ, Goldberg SR, Kuhar MJ (1987) Cocaine receptors on dopamine transporters are related to self-administration of cocaine. Science 237:1219-1223.

Robertson MW, Leslie CA, Bennett JP Jr (1991) Apparent synaptic dopamine deficiency induced by withdrawal from chronic cocaine treatment. Brain Res 538:337-339.

Robbins TW (1991) The case for frontostriatal dysfunction in schizophrenia. Schizophr Bull 16:391-402.

Robinson TE, Becker JB (1986) Enduring changes in brain and behavior produced by chronic amphetamine administration: a review and evaluation of animal models of amphetamine psychosis. Brain Res Rev 11:157-198.

Robinson TE, Kolb B (1998) Persistent structural modifications in nucleus accumbens and prefrontal cortex neurons produced by previous experience with amphetamine. J Neurosci 17:8491-8497.

Robinson TE, Berridge KC (1993) The neural basis of drug craving: an incentive-sensitization theory of addiction. Brain Res Rev 18:247-291.

Rorig B, Sutor B (1996) Nitric-oxide-stimulated increase in intracellular cGMP modulates gap junction coupling in rat neocortex. NeuroReport 7:569-572.

Rorig B, Klausa G, Sutor B (1995) Dye coupling between pyramidal neurons in developing rat prefrontal and frontal cortex is reduced by protein kinase A activation and dopamine. J Neurosci 15:7386-7400.

Schultz W, Apicella P, Scarnati E, Ljungberg T (1992) Neuronal activity 
in monkey ventral striatum related to the expectation of reward. J Neurosci 12:4595-4610.

Segal SD, Kuczenski R (1992) Repeated cocaine administration induces behavioral sensitization and corresponding decreased extracellular dopamine responses in caudate and accumbens. Brain Res 577:351-355.

Smith JA, Mo Q, Guo H, Kunko PM, Robinson SE (1995) Cocaine increases extraneuronal levels of aspartate and glutamate in the nucleus accumbens. Brain Res 683:264-269.

Steriade M, Amzica F, Contreras D (1996) Synchronization of fast $(30-40 \mathrm{~Hz})$ spontaneous cortical rhythms during brain activation. J Neurosci 16:392-417.

Stewart WW (1978) Functional connections between cells as revealed by dye-coupling with a highly fluorescent naphalimide tracer. Cell 14:741-759.

Sulzer D, Chen T-K, Lau YY, Kristensen H, Rayport S, Ewing A (1995) Amphetamine redistributes dopamine from synaptic vesicles to the cytosol and promotes reverse transport. J Neurosci 15:4102-4108.

Valadez A, Schenk S (1994) Persistence of the ability of amphetamine preexposure to facilitate acquisition of cocaine-self administration. Pharmacol Biochem Behav 47:203-205.

White FJ, Wang RY (1984) Electrophysiological evidence for A10 dopamine autoreceptor subsensitivity following chronic D-amphetamine treatment. Brain Res 309:283-292.

White FJ, Wolf ME (1991) Psychomotor stimulants. In: The biological basis of drug tolerance and dependence (Pratt JA, ed) pp 153-197. London: Academic.

White FJ, Hu X-T, Zhang XF, Wolf ME (1995) Repeated administration of cocaine or amphetamine alters neuronal responses to glutamate in the mesoaccumbens dopamine system. J Pharmacol Exp Ther 273:445-454.

Wilson CJ (1987) Morphology and synaptic connections of crossed corticostriatal neurons in the rat. J Comp Neurol 263:567-580.

Wilson CJ, Kawaguchi Y (1996) The origin of two-state spontaneous membrane potential fluctuations of neostriatal spiny neurons. J Neurosci 16:2397-2410.

Williams SM, Goldman-Rakic PS (1998) Widespread origin of the primate mesofrontal dopamine system. Cereb Cortex 8:321-345.

Wise RA (1996) Neurobiology of addiction. Curr Opin Neurobiol 6:243-251.

Wolf ME, White FJ, Hu X-T (1994) MK-801 prevents alterations in the mesoaccumbens dopamine system associated with behavioral sensitization to amphetamine. J Neurosci 14:1735-1745.

Wolf ME, Dahlin SL, Hu X-T, Xue C-J, White K (1995) Effects of lesions of prefrontal cortex, amygdala, or fornix on behavioral sensitization to amphetamine: comparison with $N$-methyl-D-aspartate antagonists. Neuroscience 69:417-439.

Yang CR, Seamans JK, Gorelova N (1996) Electrophysiological and morphological properties of layers V-VI principal pyramidal cells in rat prefrontal cortex in vitro. J Neurosci 16:1904-1921.

Yang QZ, Hatton GI (1999) Nitric oxide via cGMP-dependent mechanisms increases dye coupling and excitability of rat supraoptic nucleus neurons. J Neurosci 19:4270-4279.

Yim CY, Morgenson GJ (1988) Neuromodulatory action of dopamine in the nucleus accumbens: an in vivo intracellular study. Neuroscience 26:403-415. 